an important and perhaps not unintended effect of this book may be to stimulate a fundamental revision of the teaching of anatomy. It would appear that the medical scientist is now in much the same position as his physics colleagues, faced with the need to incorporate the findings of atomic and nuclear research into the classical treatment of physics. In the end, the only solution must be a radical $r e$-writing of the whole syllabus of anatomy, taking into account the evidence of electron microscopy and more fundamentally still of biomolecular studies. Prof. Causey's book may well prove to be a valuable contribution to this process providing, as it does, a conspectus of the whole field of ultra-structural anatomy. If it is in order from a comparative outsider, the author is to be congratulated on a pioneering effort. It may well be more valuable and have wider repercussions than he anticipated.

V. E. Cosslett

\section{HYPERSONIC FLOW RESEARCH}

Hypersonic Flow Research

Edited by Frederick R. Riddell. A Selection of Technical Papers based mainly on a Symposium of the American Rocket Society held at the Massachusetts Institute of Technology, Cambridge, Mass., August 16-18, 1961. (Progress in Astronautics and Rocketry, Vol. 7.) Pp. $\mathrm{x}+758$. (Now York: Academic Press, Inc.; London: Academic Press, Inc. (London), Ltd., 1962.) $84 s$.

TNTERNATIONAL conferences on specialized subjects 1 are by no means rare. However, there can have been few at which the standard of all the papers was so uniformly high as at this symposium on "Hypersonic Flow Research" organized by the American Rocket Society. Largely this must be ascribed to the procedure whereby the chairmon of each session were involved at the outset in selecting the papers in their particular field. Naturally the emphasis on space research in the United States ensured that there would be a very large number of contributed papers from which to choose. Chauvinists will be pleased to note that three of the papers originated in Britain. It is perhaps unfortunate that, owing to political difficulties, the scheduled papers from the U.S.S.R. were not forthcoming.

In view of the difficulty of simulating the conditions of hypersonic flight for model testing in ground facilities it is not surprising that the largest number of papers is concerned with experimental techniques. Although it is clear from these papers that astonishing advances have been made, much remains to be done in improving the uniformity of flow conditions in short running-time facilities and in developing instrumentation for the accurate measurement of aerodynamic quantitios. It is also clear that all the different facilities described have a place in hypersonic research, since no one piece of equipment can provide full simulation of enthalpy and Reynolds number.

The remaining papers are divided into three groups, flow at low Reynolds number, inviseid flows, and chemical kinetic effects including investigations of the radiation from high-temperature air. The emphasis in theoretical work on low-density effects is towards extending continuum theories, and in particular the boundary layer approximation, to lower Reynolds numbers. Van Dyke's paper especially is of this nature, and he applies the method of inner and outer expansions to obtain second-order terms in the boundary-layer solution for a sphere at infinite Mach number. The results of Levinsky and Yoshihara show how the boundary-layer and shock-wave gradually increase in thickness with decreasing density (increasing altitude) until finally they merge into one viscous shock layer. Although the work reported here seems to confirm an earlier result that there is only a narrow region of perhaps 10 miles in altitude separating the régimes of near-free-molecule flow on one hand and extensions of continuum theory to lower densities on the other, there is still no clear answer available to the question of what is the lower limit of the Reynolds number at which continuum theories remain valid.

In the group of papers on chemical kineties, Bauer's paper is an extremely useful introduction to the problem of incorporating chemical reactions into hypersonic flows. Vaglio-Laurin and Bloom present a general study of methods of calculating the inviscid flow around practical re-entry shapes and show how data on reaction rates can be fed-in so as to determine their effects on the flow field. Other papers in this section describe experimental work on the properties of high-temperature air and, in particular, the radiation and the rates of the various chemical reactions in air at the high temperatures associated with re-entry at satellite speeds and greater.

Finally, there is a very interesting group of analytical papers on inviscid hypersonic flows. In particular the entropy layer composed of particles which passed through the strong, nearly normal part of the bow shock wave near the surface of a slender body in hypersonic flow received some emphasis, and apparently a heated discussion arose on the applicability of the blast-wave analogy in such cases.

Although the conference was intended to report on present-day research problems, many of these are still unresolved and much work is still going on. Further, the papers in this volume remain as perhaps the best basis for future work.

L. F. Crabtree

\section{NEURAL COMPUTATION}

\section{The Brain as a Computer}

By F. H. George. (International Series of Monographs on Pure and Applied Biology. Division: Zoology, Vol. 8.) Pp. vii +413 . (London and New York: Pergamon Press, 1961.) 63s. net.

THIS book may be considered as a kind of meta-textbook for the behavioural sciences, in which is presented a treatment of the logic and mathematics underlying the basic design problems of life-like machines, together with an account of the neuro-physiology of the brain. In the author's words it is "an attempt to provide a conceptual framework for experimental psychology, and even experimental biology generally", and it is not particularly concerned with the immediate evidence.

The book is written in clear and precise language, and it is well produced and furnished with clear diagrams, all which are relevant to the text.

The range of topics covered is vast, including as it does: philosophy of science, with a general acceptance of Braithwaite's position as set out in Scientific Explanation; the basis of mathematics and logic; a short treatment of matrix algebra and the use of symbolic logic, particularly "logical nets" following McCullough and Pitts, together with a little circuit theory showing practical 'and' and 'or' circuits. The author goes on to describe various models which have been put forward, including Turing's basic work on his universal machine, and the more special models of Uttley and Ross Ashby, together with a de. scription and circuit of Grey Walter's mechanical tortoise, Machina speculatrix. There follows a section on learning: a short text-book treatment of the central nervous system, and finally a discussion of some of the problems of perception. All this represents a great deal of ground to cover, and one feels that, in the author's view, this kind of knowledge should be a pre-requisite of the experimental psychologist, and more or less obligatory to those who aspire to undertake experiments designed to elucidate the functional processes of the nervous system.

To justify the author's demanding selection of intellectual skills required by experimental psychologists, it would be necessary to show that understanding of 